\title{
Electronic Records Control
}

National Cancer Institute

\section{Source}

National Cancer Institute. Electronic Records Control. NCI Thesaurus. Code C142532.

The preparation and maintenance of electronic clinical trial records. 